\title{
PROCESSO DE FORMAÇÃO DE CROSTAS SUPERFICIAIS EM RAZÃO DE SISTEMAS DE PREPARO DO SOLO E CHUVA SIMULADA $^{(1)}$
}

\author{
Jaqueline Dalla Rosa ${ }^{(2)}$, Miguel Cooper ${ }^{(3)}$, Frédéric Darboux $^{(4)}$ \& João Carlos Medeiros ${ }^{(2)}$
}

\section{RESUMO}

A chuva provoca a modificação da estrutura superficial do solo levando ao desenvolvimento de crostas. Este estudo avaliou a dinâmica da formação de crostas superficiais por meio da análise e descrição micromorfológica de lâminas delgadas. O experimento foi conduzido em 2009 e 2010 . Em parcelas de 15 x 30 m, foram implantados os diferentes sistemas de preparos do solo: preparo convencional (PC), preparo reduzido (PR) e sem preparo (SP). Dentro das parcelas instalaramse as microparcelas de $1 \times 1 \mathrm{~m}$ e aplicaram-se diferentes lâminas de chuva simulada $(0,27,54$ e $80 \mathrm{~mm})$ com intensidade de $80 \mathrm{~mm} \mathrm{~h}^{-1}$. Nas microparcelas, coletou-se uma amostra indeformada em que consistia em um bloco de solo de 0,07 x $0,05 \times$ $0,12 \mathrm{~m}$. Os blocos foram impregnados com resina e após endurecimento e secagem total foram confeccionadas lâminas delgadas $(4,5 \times 8 \mathrm{~cm})$, descritas, utilizando microscópio óptico. Foi confeccionada uma lâmina delgada para cada chuva $(0,27$, 54 e $80 \mathrm{~mm}$ ) e para cada preparo do solo. Todos os sistemas de preparo avaliados demonstraram presença de crostas; entretanto, o processo de formação das crostas ocorreu com dinâmica diferenciada em cada sistema de preparo. $O$ preparo convencional apresentou formação de crostas a partir de $27 \mathrm{~mm}$ de chuva aplicada. O aumento da lâmina de chuva aplicada causou maior degradação da estrutura superficial e maior espessura da camada encrostada. $O$ preparo reduzido e o sistema sem preparo apresentaram condições de superfície irregulares com as chuvas aplicadas, ou seja, não demonstraram modificações constantes da superfície do solo e na formação das crostas, com o aumento da chuva, como constatado no

(1) Parte da Tese de Doutorado do primeiro autor, apresentada ao Programa de Pós Graduação de Solos e Nutrição de Plantas, Escola Superior de Agricultura "Luiz de Queiroz" - ESALQ/USP. Recebido para publicação em 23 de maio de 2012 e aprovado em 5 de fevereiro de 2013.

(2) Pós doutorando, Embrapa Arroz e Feijão - CNPAF. Rodovia GO-462, km 12, Zona Rural. Caixa Postal 179. CEP 75375-000 Santo Antônio de Goiás (GO), Brasil. E-mail: jaqueline.dr@gmail.com; medeiros.jc@gmail.com

(3) Professor, Universidade de São Paulo, Escola Superior de Agricultura "Luiz de Queiroz", Departamento Ciência do Solo, Avenida Pádua Dias, 11, CEP 13418-900 Piracicaba/SP. E-mail: mcooper@usp.br

(4) Pesquisador, INRA, UR 0272 Science du sol, Centre de Recherche d'Orléans, CS 40001, F-45075 Orléans Cedex 2, France. Email: frederic.darboux@orleans.inra.fr 


\begin{abstract}
preparo convencional. A análise das lâminas delgadas e a descrição micromorfológica permitiram satisfatória observação e conclusão dos processos e da dinâmica envolvida na formação de crostas.
\end{abstract}

\author{
Termos de indexação: encrostamento, micromorfologia, lâminas delgadas, preparo \\ convencional, preparos conservacionistas.
}

\title{
SUMMARY: INFLUENCE OF TILLAGE SYSTEMS AND SIMULATED RAINFALL ON THE PROCESS OF SURFACE CRUST FORMATION
}

\begin{abstract}
On the soil surface, rainfall modifies the soil surface structure promoting crust development. This study evaluated the dynamics of soil crusting, through description and micromorphological analysis of thin sections in 2009 and 2010. In $15 \times 30 \mathrm{~m}$ plots, the management systems conventional tillage $(C T)$, reduced tillage (RT) and no tillage (NT) were assessed. Within the plots, $1 \times 1 \mathrm{~m}$ micro-plots were installed to test different levels of simulated rainfall $(0,27,54$, and $80 \mathrm{~mm}$ ) at an intensity of $80 \mathrm{~mm} \mathrm{~h}^{-1}$. From these micro-plots, an undisturbed sample (soil block of $0.07 \times 0.05 \times 0.12 \mathrm{~m}$ ) was taken. The blocks were resin-impregnated and after hardening and drying, thin sections $(4.5 \times 8 \mathrm{~cm})$ were prepared and described using optical microscopy. One thin section was prepared per rainfall level and soil tillage system. Crusts were formed in all tillage systems, however, the process of crust formation was different in each system. Under conventional tillage, crusting was observed after $27 \mathrm{~mm}$ rain. A higher rain level increased the degradation of the surface structure and thickness of the crust layer. Under reduced tillage and no-tillage the surface conditions were irregular after the applied rainfall, i.e., the changes in the soil surface and in crust formation were not constant with increasing rain levels, unlike under conventional tillage. The analysis of thin sections and micromorphological description allowed satisfactory conclusions on the processes and dynamics involved in crust formation.
\end{abstract}

Index terms: crusting, micromorphology, thin sections, conventional tillage, conservation tillage systems.

\section{INTRODUÇÃO}

A ação direta da chuva na superfície do solo e a deposição de partículas, decorrentes da quebra dos agregados, provocam a modificação da estrutura superficial do solo, levando ao desenvolvimento de crostas. As alterações das condições superficiais dependem das caracteristicas do solo como textura, mineralogia, matéria orgânica, umidade inicial, distribuição, tamanho e estabilidade dos agregados etc (Fox \& Le Bissonnais, 1998; Le Bissonnais \& Singer, 1993), bem como dos fatores climáticos, especialmente da chuva (intensidade, distribuição de tamanho de gota, energia cinética), além da cobertura vegetal, atividade biológica e uso da terra (Le Bissonnais et al., 2005). A crosta pode ser definida como uma camada de espessura variável, densa e dura que ocorre na superfície do solo; é caracterizada por apresentar maior densidade e resistência à penetração, além de poros menores e baixa condutividade hidraúlica (Shainberg et al., 1992).

As crostas superficiais ocorrem sob chuva ou irrigação, envolvendo dois estágios principais. O primeiro é a quebra da estrutura superficial (agregados) em finos fragmentos e, ou, partículas primárias, que envolvem vários processos como quebra por umedecimento rápido (slaking), em razão da compressão do ar aprisionado no interior dos agregados e dispersão físico-química da argila. O segundo ocorre pela redistribuição das partículas e, ou, pelos fragmentos dispersos, concentrando no topo da superfície do solo, em alguns poucos milímetros (Bresson \& Valentin, 1993; Lado et al., 2004; Ries \& Hirt, 2008). No primeiro estágio, serão originadas as crostas denominadas de estruturais e, no segundo, as crostas deposicionais, também conhecidas como sedimentares, ou seja, crostas estruturais são caracterizadas pelo rearranjamento in situ das partículas sem evidências de movimento lateral. Já as crostas deposicionais são formadas pela translocação de partículas finas depositadas a curtas distâncias da origem e, as crostas erosionais consistem em somente uma fina, rígida e lisa camada superficial enriquecida de finas partículas (Valentin \& Bresson, 1992).

O estudo e o detalhamento do processo de formação de crostas do solo podem ser monitorados diretamente por meio da mudança da morfologia ou indiretamente por diminuição da capacidade de infiltração ou aumento na resistência da superfície. Muitos cientistas, desde Duley (1939), incluem a necessidade de usar microscópio em estudos de crostas, por meio de análises micromorfológicas (Valentin \& Bresson, 1992). A análise micromorfológica permite observar os componentes estruturais do solo, possibilitando melhor visualização do comportamento da estrutura e do 
espaço poroso em áreas sob processo de degradação (Lima et al., 2005). Essa técnica permite ainda observar características como a espessura da crosta, a porosidade, que inclui distribuição, forma, continuidade e tamanho de poros. A utilização das técnicas de monitoramento direto (análises micromorfológicas), associadas ao monitoramento indireto (testes de infiltração, condutividade hidráulica, teste de resistência da superfície, entre outros) é o mais aconselhável (Valentin \& Bresson, 1997), pois dessa forma pode-se obter maior detalhamento, abordando as mudanças micromofológicas na estrutura superficial do solo, assim como a consequência dessa sobre a porosidade, condutividade e infiltração de água, entre outros.

A degradação da superfície do solo pelas crostas ocorre em razão do adensamento, da obstrução e redução dos poros e do aumento da resistência hidráulica. Essas consequências causam a redução da infiltração e da condutividade da água (McIntyre, 1958; Valentin \& Bresson, 1992; Fox et al., 1998; Brandão et al., 2006; Bedaiwy, 2008; Ries \& Hirt, 2008) e, consequentemente, favorecem a erosão e degradação ambiental. A maioria dos estudos sobre formação de crostas baseia-se no detalhamento do processo nos sistemas de preparo que envolvem o revolvimento do solo; pouco se sabe, no entanto, sobre a dinâmica desse processo em sistemas conservacionistas. Schaefer et al. (2002), avaliando a formação de crostas em razão da percentagem de cobertura do solo, observaram que os solos mais expostos, com cobertura variando de 0 a $20 \%$, apresentaram formação de crosta erosional, enquanto os solos com superfície coberta integralmente (100\% de cobertura) não apresentaram crostas. É fato que os sistemas conservacionistas mobilizam minimamente o solo, mantendo a maior parte dos resíduos culturais como estratégia para evitar a erosão; entretanto, muito pouco ainda é conhecido sobre o processo de formação de crostas em condições de preparos conservacionistas.

Este estudo teve como objetivo avaliar a dinâmica da formação de crostas superficiais por meio da análise e descrição micromorfológica de lâminas delgadas, em um Argissolo Vermelho-Amarelo conduzido com três sistemas de preparo do solo e aplicação de chuva simulada.

\section{MATERIAL E MÉTODOS}

O experimento foi realizado em Piracicaba, SP, Brasil (22 42" S, $47^{\circ} 36^{\circ}$ W) sobre um Argissolo Vermelho-Amarelo de textura arenosa (Embrapa, 2006). Os atributos químicos do solo para a camada de 0-20 cm são: $\mathrm{pH}$ em $\mathrm{CaCl}_{2}=5,11 ; \mathrm{MO}=32 \mathrm{~g} \mathrm{dm}^{-3}$; $\mathrm{P}=5 \mathrm{~g} \mathrm{dm}^{-3} ; \mathrm{K}=0,8 \mathrm{mmol}_{\mathrm{c}} \mathrm{dm}^{-3} ; \mathrm{Ca}=23 \mathrm{mmol}_{\mathrm{c}} \mathrm{dm}^{-3}$; $\mathrm{Mg}=12 \mathrm{mmol}_{\mathrm{c}} \mathrm{dm}^{-3} ; \mathrm{H}+\mathrm{Al}=28 \mathrm{mmol}_{\mathrm{c}} \mathrm{dm}^{-3} ; \mathrm{Al}=$ $0,43 \mathrm{mmol}_{\mathrm{c}} \mathrm{dm}^{-3} ; \mathrm{SB}=35,8 \mathrm{mmol}_{\mathrm{c}} \mathrm{dm}^{-3} ; \mathrm{CTC}$ efetiva
$=63,8 \mathrm{mmol}_{\mathrm{c}} \mathrm{dm}^{-3} ; \mathrm{e} \mathrm{V}=56 \%$. A composição granulométrica do solo estudado, com fracionamento da areia para a camada de $0-5 \mathrm{~cm}$, e descrição granulométrica geral para as demais camadas encontram-se no quadro 1.

O clima da região é tropical Cwa, segundo classificação de Köppen. O relevo é suavemente ondulado e a altitude é de $542 \mathrm{~m}$. A precipitação pluvial média anual para os 10 últimos anos foi de $1.193 \mathrm{~mm}$. As três chuvas máximas mensais, em $24 \mathrm{~h}$, observadas durante esse período ocorreram em março de 2002, maio de 2005 e janeiro de 2008 com 104,139 e $87 \mathrm{~mm}$, respectivamente, de acordo com a base de dados metereológicos da USP/ESALQ, em 2011.

O experimento foi realizado durante dois anos (2009 e 2010). Em novembro de 2008, realizou-se o preparo inicial do solo em toda área experimental (uma aração + três gradagens) para padronizar as condições de superfície do solo; após, realizou-se a implantação de uma cultura de cobertura (Brachiaria decumbens Stapf.), semeada a lanço, sem incorporação, com densidade de semeadura de $13 \mathrm{~kg} \mathrm{ha}^{-1}$.

\section{Primeiro ano de condução do experimento (2009)}

No início de abril de 2009, a braquiária encontravase em estádio de pleno desenvolvimento, procedendose então à roçada da massa vegetal com roçadeira motorizada manual. $\mathrm{O}$ controle da rebrota das plantas foi realizado por dessecação com herbicida sistêmico Glyfosato, na dosagem de 4,0 $\mathrm{L} \mathrm{ha}^{-1}$. A matéria seca produzida pela braquiária, na área de estudo, foi de $8.400 \mathrm{~kg} \mathrm{~h}^{-1}$. Em junho de 2009, foram realizados os tratamentos que corresponderam a três sistemas de preparo do solo, com diferentes intensidades de revolvimento: preparo convencional (PC), realizado com uma aração e duas gradagens; preparo reduzido (PR), com uma gradagem pesada; e sem preparo (SP), sem movimentação na superfície do solo. As profundidades do preparo consistiram de 25 a $30 \mathrm{~cm}$, no PC, e 15 a $20 \mathrm{~cm}$, no PR. Após cada preparo realizado, a cobertura remanescente na superfície do solo foi de 0; 70 a 80 e $100 \%$ para PC, PR e SP, respectivamente.

Cada tratamento (preparo do solo) constituiu em uma parcela de $7 \times 30 \mathrm{~m}$, em que foram instaladas as microparcelas de $1 \times 1 \mathrm{~m}$. Nessas, aplicaram-se diferentes lâminas de chuva simulada $(0,27,54$ e 80 $\mathrm{mm})$; para cada lâmina, realizaram-se três repetições, em microparcelas diferentes. A intensidade da chuva simulada foi de $80 \mathrm{~mm} \mathrm{~h}^{-1}\left( \pm 5 \mathrm{~mm} \mathrm{~h}^{-1}\right)$, aplicada logo após a realização dos preparos do solo, com um simulador de chuvas operando a uma altura de $2,4 \mathrm{~m}$ sobre o solo. O simulador é composto por um bico em leque pendular, do tipo VeeJet Spray Nozzle (H/U80100, Spraying Systems, Co.). A área de abrangência atingida pela chuva foi de $1 \mathrm{~m}^{2}$. 
Quadro 1. Descrição granulométrica do Argissolo Vermelho-Amarelo estudado

\begin{tabular}{|c|c|c|c|c|c|c|c|c|}
\hline \multirow{2}{*}{ Camada } & \multirow{2}{*}{ Argila } & \multirow{2}{*}{ Silte } & \multicolumn{6}{|c|}{ Areia } \\
\hline & & & Muito grossa & Grossa & Média & Fina & Muito fina & Total \\
\hline $\mathrm{cm}$ & & & - & g & & & & \\
\hline $0-5$ & 164 & 20 & 6 & 20 & 155 & 471 & 164 & 816 \\
\hline $0-20$ & 179 & 38 & - & - & - & - & - & 783 \\
\hline $40-60$ & 257 & 52 & - & - & - & - & - & 691 \\
\hline $80-100$ & 262 & 37 & - & - & - & - & - & 701 \\
\hline
\end{tabular}

\section{Coleta e impregnação das amostras descrição das lâminas delgadas}

As amostras para a análise micromorfológica foram coletadas na área experimental $24 \mathrm{~h}$ após a realização da simulação de chuva. Em cada microparcela, coletou-se uma amostra indeformada, que consistia em um bloco de solo vertical de $0,07 \times 0,05 \times 0,12 \mathrm{~m}$, orientado à superfície e acomodado em caixas de papel confeccionadas para esse fim.

No laboratório, os blocos foram secos ao ar e posteriormente em estufa. A impregnação foi realizada de acordo com método proposto por Murphy et al. (1977), Murphy (1986) e Castro et al. (2003). Depois de os blocos estarem totalmente impregnados e endurecidos, foram cortadas fatias, de aproximadamente $0,5 \mathrm{~cm}$ de espessura, verticais e orientadas à superfície, das quais foi confeccionada uma lâmina delgada de seção fina $(4,5 \times 8 \mathrm{~cm})$ para microscópio óptico. Foi confeccionada uma lâmina delgada para cada chuva aplicada $(0,27$, 54 e $80 \mathrm{~mm}$ ) e cada preparo do solo, totalizando 12 lâminas para 2009 e 12, para 2010. As lâminas delgadas foram confeccionadas no laboratório de Ciência do Solo do INRA (UR Science du Sol - INRA), em Orléans, na França. As fatias foram inicialmente coladas em uma lâmina de vidro $(4,5 \times 8 \mathrm{~cm})$ e posteriormente a face do bloco foi polida em uma lixadeira mecânica. Em seguida, o polimento fino foi realizado manualmente com carbureto de silício verde (600 mesh com grãos de 18 a $22 \mu \mathrm{m}$ ), até as lâminas atingirem a espessura desejada $(30 \mu \mathrm{m})$, tomando-se sempre o cuidado para que a espessura fosse uniforme em toda a lâmina e fazendo o controle da espessura ao microscópio por meio da extinção padrão do quartzo presente.

A descrição micromorfológica ocorreu inicialmente com um exame prévio em lupa, a fim de se observarem as feições e a caracterização geral da lâmina em razão das lâminas de chuva e do preparo do solo aplicado. Posteriormente, com auxílio do microscópio óptico, procedeu-se nas lâminas delgadas a descrição micromorfológica, seguindo os critérios propostos por Bullock et al. (1985). Realizou-se a descrição da dinâmica do processo de formação e modificação das crostas por causa das lâminas de chuva aplicada nos diferentes preparos do solo. As crostas observadas em cada sistema de preparo foram classificadas, conforme sugerem Valentin \& Bresson (1992).

\section{Segundo ano de condução do experimento (2010)}

Após as coletas de solo, em junho de 2009, a área experimental permaneceu em pousio até novembro de 2009, quando realizou-se a ressemeadura da braquiária (13 kg ha-1) e adubação nitrogenada de cobertura com $200 \mathrm{~kg}^{-1}$ de $\mathrm{N}$, realizadas a lanço sem incorporação. Todas as etapas seguintes até o momento da segunda coleta, em junho de 2010 , foram realizadas da mesma forma que na anterior, em 2009. A massa seca produzida pela braquiária, na área de estudo em 2010, foi de $10.400 \mathrm{~kg} \mathrm{~h}^{-1}$. Nesse segundo ano de experimento, a percentagem de cobertura remanescente após o preparo na superfície do solo foi de 0,80 a 85 e $100 \%$ para $\mathrm{PC}, \mathrm{PR}$ e SP, respectivamente.

É importante ressaltar que durante o período de pousio, período que antecedeu a realização dos preparos, dezembro de 2008 a maio de 2009 e julho de 2009 até maio de 2010, a área experimental foi atingida pelas chuvas naturais. Especialmente nos preparos menos revolvidos como o PR e SP, a chuva natural pode ter influenciado a dinâmica de modificação da estrutura superficial do solo e, consequentemente, a formação de crostas. Em razão disso, salienta-se que as chuvas naturais acumuladas para o período de estudo foram de $554 \mathrm{~mm}$ (dezembro de 2008 a maio de 2009) e $1.348 \mathrm{~mm}$ (julho de 2009 a maio de 2010), de acordo com a base de dados meteorológicos USP/ ESALQ, em 2011.

\section{RESULTADOS E DISCUSSÃO}

\section{Formação de crostas no $\mathrm{PC}$ em razão das lâminas de chuva aplicada}

A degradação da superfície do solo e o consequente processo de formação das crostas foram semelhantes nos dois anos de estudo para esse sistema de preparo. Após a realização do preparo do solo, esse se encontrava bastante revolvido e desagregado em razão do intenso preparo. A aplicação da chuva sobre o solo revolvido e descoberto causou degradação da estrutura superficial levando a formação de crostas. 
Os agregados foram quebrados e o material da superfície foi disperso pelo efeito das gotas da chuva. Posteriormente, o material desagregado e disperso foi reorganizado e orientado superficialmente. Os grãos de quartzo se dispuseram em lâminas conforme os seus tamanhos, até que se formou uma camada de grãos de quartzo, que apresentou maior espessura com aumento da lâmina de chuva aplicada $(80 \mathrm{~mm})$ (Figura 1). O material fino, que constituía a camada superficial do solo, quando atingido pela chuva, foi iluviado e se depositou formando uma lâmina abaixo da camada de grãos de quartzo (linha pontilhada vermelha na figura 1 ).

O processo de encrostamento foi muito semelhante com a aplicação de 27 e $54 \mathrm{~mm}$. Constatou-se a presença de uma camada de grãos de quartzo limpos moderadamente a bem selecionados, de maior tamanho na parte superior e menor tamanho mais abaixo (Figura 1, Quadro 2). Quando a lâmina de chuva aumentou para $80 \mathrm{~mm}$, a crosta formada apresentou
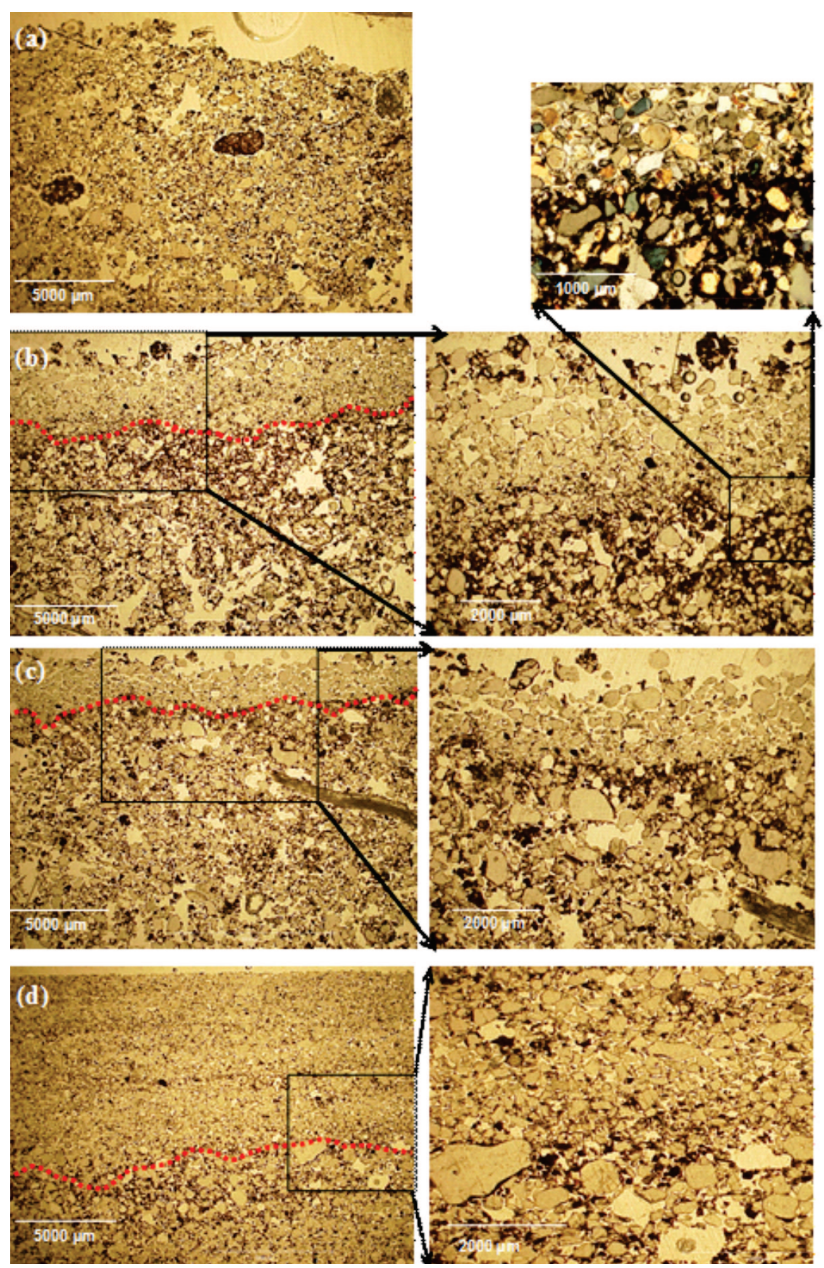

Figura 1. Detalhes da crosta formada no PC em razão das lâminas de chuva aplicada sobre um Argissolo Vermelho-Amarelo (Piracicaba, SP). (a), (b), (c) e (d) correspondem a 0, 27, 54 e 80 mm, respectivamente. maior espessura e constatou-se, da mesma forma que nas chuvas anteriores, a presença de camadas de grãos de quartzo verticalmente selecionados, conforme o tamanho (Figura 1d). Verificaram-se camadas de acúmulo de grãos de quartzo de maior tamanho intercaladas com laminações de material fino e camadas de grãos de quartzo de tamanho pequeno. A porosidade predominante nas diferentes áreas da lâmina foi do tipo empilhamento e cavidades irregulares (Brewer, 1964; Bullock et al., 1985; Castro et al., 2003) (Figura 1, Quadro 2). Os poros do tipo empilhamento são resultantes do empacotamento de grãos de material grosseiro ou agregados; esses são irregulares e orientados ao acaso. Já as cavidades são poros relativamente grandes que apresentam formas esféricas a alongadas, às vezes irregulares (Castro et al., 2003).

As crostas observadas no PC foram classificadas como estruturais do tipo Sieving, segundo a classificação proposta por Valentin \& Bresson (1992). Essas são desenvolvidas primeiramente pelo impacto das gotas, formando microdepressões; com a infiltração de água o material disperso se dispõe e se organiza em camadas. A diferença de tamanho de grãos de quartzo e o acúmulo de material fino dentro das crostas formadas (Figura 1b,c,d) resultam principalmente de peneiração mecânica (sieving), de modo que as partículas finas se depositam mais profundamente (Valentin \& Bresson, 1992). Além disso, a translocação da argila e o acúmulo numa fina camada podem ser explicados pela percolação de água. As principais feições micromorfológicas como classificação, empacotamento e orientação de partículas grossas e finas são relacionadas e dependentes das condições hidrodinâmicas de sedimentação das partículas (Bresson \& Boiffin, 1990; Valentin \& Bresson, 1992).

As crostas superficiais foram também denominadas como um processo pedogenético de concentração (Jongerius, 1970). Esse processo resulta principalmente das acumulações de componentes sólidos do solo por causa da mobilização ou separação. Os componentes normalmente movem-se até certa profundidade do perfil (iluviação) antes de se concentrarem, podendo também depositar no mesmo lugar onde houve o desprendimento (Jongerius, 1970).

\section{Formação de crostas no PR em função das lâminas de chuva aplicada}

Neste sistema de preparo foi constatada a presença de crostas, entretanto, as modificações observadas na superfície do solo e a formação de crostas não foram persistentes com o aumento das lâminas de chuva aplicada, como observado no PC.

A superfície do solo apresentou-se bastante perturbada, com disposição irregular, e em algumas zonas houve presença incipiente de material organizado por camadas intercaladas com grãos de quartzo de tamanho grande, pequeno e laminações de 


\section{Quadro 2. Descrição micromorfológica para o sistema PC em razão das lâminas de chuva aplicada sobre um Argissolo Vermelho-Amarelo}

\begin{tabular}{|c|c|c|c|c|}
\hline \multirow{2}{*}{ Atributo } & \multicolumn{4}{|c|}{ Preparo convencional } \\
\hline & $0 \mathrm{~mm}$ & $27 \mathrm{~mm}$ & $54 \mathrm{~mm}$ & $80 \mathrm{~mm}$ \\
\hline Geral & $\begin{array}{l}\text { Distribuição } \\
\text { homogênea de } \\
\text { material }\end{array}$ & $\begin{array}{l}\text { Distribuição heterogênea de } \\
\text { material. Três zonasA ( } 40 \%) \text {, } \\
\text { B (50\%) e C (10 \%) dividido em } \\
\text { C1 e C2 }\end{array}$ & $\begin{array}{l}\text { Distribuição } \\
\text { heterogênea de } \\
\text { material. Três zonasA } \\
\text { (20\%), B ( } 70 \%) \text { e C (10 \%) } \\
\text { dividido em C1 e C2 }\end{array}$ & $\begin{array}{l}\text { Distribuição heterogênea de } \\
\text { material. Três zonas A ( } 20 \%) \\
\text { B }(60 \%) \text { e C }(20 \%) \text { dividido } \\
\text { em C1 e C2 }\end{array}$ \\
\hline $\begin{array}{l}\text { Micro - } \\
\text { estrutura }\end{array}$ & $\begin{array}{l}\text { Blocos } \\
\text { subangulares com } \\
\text { pedalidade fraca a } \\
\text { moderadamente } \\
\text { desenvolvida }+ \\
\text { Granular com } \\
\text { pontes e películas }\end{array}$ & $\begin{array}{l}\text { A) Microagregados granulares } \\
\text { + Granular com pontes e } \\
\text { películas; Moderada a } \\
\text { fracamente desenvolvida;B) } \\
\text { Blocos subangulares; } \\
\text { fracamente desenvolvidos C1) } \\
\text { Granular com pontes e } \\
\text { películas (10\%); C2) Grãos } \\
\text { simples (90\%) }\end{array}$ & $\begin{array}{l}\text { A) Microagregados } \\
\text { granulares fracamente } \\
\text { desenvolvidos + } \\
\text { Granular com pontes e } \\
\text { películas; B) Blocos } \\
\text { subangulares; } \\
\text { fracamente } \\
\text { desenvolvidos + } \\
\text { granular com pontes; } \\
\text { C1) Microgranular } \\
\text { adensada; C2) Grãos } \\
\text { simples }\end{array}$ & $\begin{array}{l}\text { A) Blocos subangulares; } \\
\text { moderadamente } \\
\text { desenvolvidos + } \\
\text { Microagregados granulares; } \\
\text { B) Granular com pontes e } \\
\text { películas + microgranular } \\
\text { adensada; C1) Microgranular } \\
\text { adensada; C2) Grãos simples }\end{array}$ \\
\hline $\begin{array}{l}\text { Material } \\
\text { fino }\end{array}$ & $\begin{array}{l}\text { Argila e matéria } \\
\text { orgânica, marrom } \\
\text { escura, }(15 \%)\end{array}$ & $\begin{array}{l}\text { Argila e matéria orgânica, } \\
\text { marrom escura.A) (20\%), B) } \\
(15 \%), \text { C1) }(20 \%) \text { e C2) (2\%) }\end{array}$ & $\begin{array}{l}\text { Argila e matéria orgânica, } \\
\text { marrom escura. } \\
\text { A) }(20 \%) \text {; B) } 15 \%) \\
\text { C1) }(20 \%) \text { e C } 2)(2 \%)\end{array}$ & $\begin{array}{l}\text { Argila e matéria orgânica, } \\
\text { marrom escura, A) }(20 \%), \text { B) } \\
(15 \%), \text { C1) }(10 \%) \text { e C } 2)(3 \%)\end{array}$ \\
\hline $\begin{array}{l}\text { Material } \\
\text { grosso }\end{array}$ & $\begin{array}{l}\text { Quartzo } \\
\text { subarredondado } \\
\text { mal selecionado } \\
(40 \%)\end{array}$ & $\begin{array}{l}\text { A) }(40 \%), \text { B) }(35 \%) \text { e C1) (45 \%), } \\
\text { Quartzo subarredondado, } \\
\text { mal selecionado, C2) }(63 \%), \\
\text { quartzo subarredondado } \\
\text { moderadamente selecionado }\end{array}$ & $\begin{array}{l}\text { A) }(40 \%), \text { B) }(35 \%) \text { e } \\
\text { C1) }(40 \%), \text { Quartzo } \\
\text { subarredondado, mal } \\
\text { selecionado; C2) (70 \%), } \\
\text { quartzo subarredondado } \\
\text { moderadamente } \\
\text { selecionado }\end{array}$ & $\begin{array}{l}\text { A) }(40 \%), \text { B) }(35 \%) \text { e C1) } \\
50 \% \text {, Quartzos } \\
\text { subarredondados, mal } \\
\text { selecionados; C2) ( } 80 \%) \text {, } \\
\text { quartzos subarredondados } \\
\text { moderadamente selecionados }\end{array}$ \\
\hline Poros & $\begin{array}{l}\text { Empilhamento } \\
\text { complexo entre } \\
\text { grãos simples e } \\
\text { pequenos } \\
\text { agregados }(60 \%)+ \\
\text { cavidades }(40 \%)\end{array}$ & $\begin{array}{l}\text { A) (40 \%) e C1 (35 \%) } \\
\text { Empilhamento composto entre } \\
\text { grãos simples e pequenos } \\
\text { agregados; B) (50 \%) } \\
\text { - Empilhamento complexo entre } \\
\text { grãos simples e pequenos } \\
\text { agregados (40 \%) } \\
\text { - Interagregados: Predomínio de } \\
\text { cavidades irregulares (30 \%) } \\
\text { - Intragregados: Predomínio de } \\
\text { cavidades (30 \%); C2) (35 \%) } \\
\text { Empilhamento simples (arranjo } \\
\text { de grãos) }\end{array}$ & $\begin{array}{l}\text { A) }(40 \%) \text { e C1) ( } 40 \%) \\
\text { Empilhamento complexo } \\
\text { entre grãos simples e } \\
\text { pequenos agregados;B) } \\
\text { (50\%) - Interagregados } \\
\text { + Intragregados com } \\
\text { predomínio de } \\
\text { cavidades; C2) (28 \%) } \\
\text { Empilhamento simples } \\
\text { (arranjo de grãos) }\end{array}$ & $\begin{array}{l}\text { A) }(40 \%) \text { e C1) ( } 40 \%) \\
\text { Empilhamento complexo entre } \\
\text { grãos simples e pequenos } \\
\text { agregados. Predomínio de } \\
\text { cavidades; B) (50 \%) } \\
\text { Empilhamento complexo + } \\
\text { Interagregados e } \\
\text { Intragregados com predomínio } \\
\text { de cavidades; C2) } \\
\text { Empilhamento simples } \\
\text { (arranjo de grãos) }\end{array}$ \\
\hline $\begin{array}{l}\text { Distribuição } \\
\text { relativa }\end{array}$ & $\begin{array}{l}\text { Quito-Gefúrica } \\
\text { com zonas } \\
\text { Porfíricas }\end{array}$ & $\begin{array}{l}\text { A) e C1) Porfiro - Enáulica; B) } \\
\text { Quitônica (30 \%) + Enáulica } \\
(70 \%) ; \text { C2) Mônica }\end{array}$ & $\begin{array}{l}\text { A) e C1)Porfiro - } \\
\text { Enáulica; B) Quitônica } \\
(40 \%)+\text { Enáulica }(60 \%) \text {; } \\
\text { C2) Mônica }\end{array}$ & $\begin{array}{l}\text { A) e C1)Porfiro - Enáulica; e } \\
\text { B) Quito - Gefúrica (40\%) + } \\
\text { Enáulica (60 \%); C2) Mônica }\end{array}$ \\
\hline $\begin{array}{c}\text { Feições } \\
\text { pedológicas }\end{array}$ & Não. & $\begin{array}{l}\text { A) não; B) não; C) Revestimento } \\
\text { do tipo crosta; Espessura: } 2 \text { a } 3 \\
\text { mm; C1) Zona de transição, } \\
\text { material fino acumulado;C2) } \\
\text { Camada de grãos de quartzos } \\
\text { acumulados, laminados } \\
\text { conforme o tamanho. }\end{array}$ & $\begin{array}{l}\text { A) não; B) não; C) } \\
\text { Revestimento do tipo } \\
\text { crosta; Espessura: } \\
1 \text { a } 2 \text { mm. C1) Zona de } \\
\text { transição, material fino } \\
\text { acumulado; C2) Camada } \\
\text { de grãos de quartzos } \\
\text { acumulados, conforme o } \\
\text { tamanho. }\end{array}$ & $\begin{array}{l}\text { A) não; B) não; C) } \\
\text { Revestimento do tipo crosta; } \\
\text { Espessura: } 6 \text { a } 8 \text { mm; C1) } \\
\text { Zona de transição, material } \\
\text { fino acumulado; C2) Camada } \\
\text { de grãos de quartzos } \\
\text { acumulados, conforme o } \\
\text { tamanho. }\end{array}$ \\
\hline
\end{tabular}


material fino. O mesmo comportamento foi constatado nos dois anos de estudo. Essas características observadas neste sistema de preparo, são decorrentes do efeito do semi-preparo associado à manutenção da cobertura o que promoveu proteção contra o impacto da gota, em partes da superfície do solo, evitando assim uma orientação das partículas em toda superfície como se observou no PC.

Onde a chuva não foi aplicada $(0 \mathrm{~mm})$, a superfície do solo apresentou certa modificação em algumas zonas, ou seja, o mesmo comportamento constatado onde aplicou-se chuva. Possivelmente, isso deve-se ao efeito da chuva natural, uma vez que o implemento utilizado no semi-preparo não atingiu a superfície do solo por completo e algumas partes da superfície mantiveram-se intactas, podendo dessa forma ter sido mantido o efeito da chuva natural. Conforme as lâminas de chuva aumentaram $(27,54$ e $80 \mathrm{~mm})$, a estrutura superficial do solo demonstrou maior perturbação e disposição irregular (Figura 2b,c,d). A orientação em profundidade de material grosso (grãos de quartzo) foi mais evidente, porém também com frequência irregular na superfície do solo, ocorrendo somente em algumas zonas.

As crostas observadas neste sistema de preparo foram diferentes das observadas no PC. O observado neste caso, mesmo que incipiente foi uma camada muito irregular com algumas feições de organização de material pelo efeito da chuva, ora por lâminas de material fino acumulado, ora por zonas com acúmulo de material grosso (Figura 2).

Essa heterogeneidade na superfície do solo deve-se às áreas que estavam mais ou menos expostas à ação da chuva. O semi-preparo realizado incorpora parcialmente a cobertura na superfície do solo, dessa forma algumas zonas ficam protegidas e outras ficam expostas. Com a aplicação crescente da chuva, as partes da superfície do solo que se encontravam descobertas foram atingidas, promovendo organização e orientação do material grosso em profundidade enquanto, que as áreas menos expostas (pelo efeito da cobertura remanescente) demonstraram acúmulo de material fino. Dessa forma, o material fino acumulado internamente na camada superficial (Figura 2) pode ser decorrente da dispersão físico-química das partículas de argila, que mantiveram-se superficialmente ou migraram internamente no solo com a infiltração de água, concentrando-se em forma de lâminas ou simplesmente acumuladas em zonas pontuais (Agassi et al., 1981).

A porosidade predominante nas crostas desse sistema de preparo foram cavidades irregulares e vesículas (Figura 2, Quadro 3). Como já descrito anteriormente, cavidades são poros relativamente grandes que apresentam formas esféricas a alongadas, às vezes irregulares. Já as vesículas são poros semelhantes às cavidades; entretanto, diferenciandose destas pelo alisamento das paredes e pela forma bem arredondada e regular (Castro et al., 2003).
Por causa da heterogeneidade, as crostas constatadas nesse sistema de preparo foram classificadas como estruturais do tipo Sieving, para as áreas atingidas diretamente pela chuva, e Slaking, para as áreas onde o material apresentou-se mais irregular, com orientação incipiente, conforme classificação de Valentin \& Bresson (1992). As crostas do tipo Slaking consistem em uma camada tipicamente apedal e geralmente não apresentam clara distinção textural como a separação entre partículas grossas e partículas finas (Valentim \& Bresson, 1992).
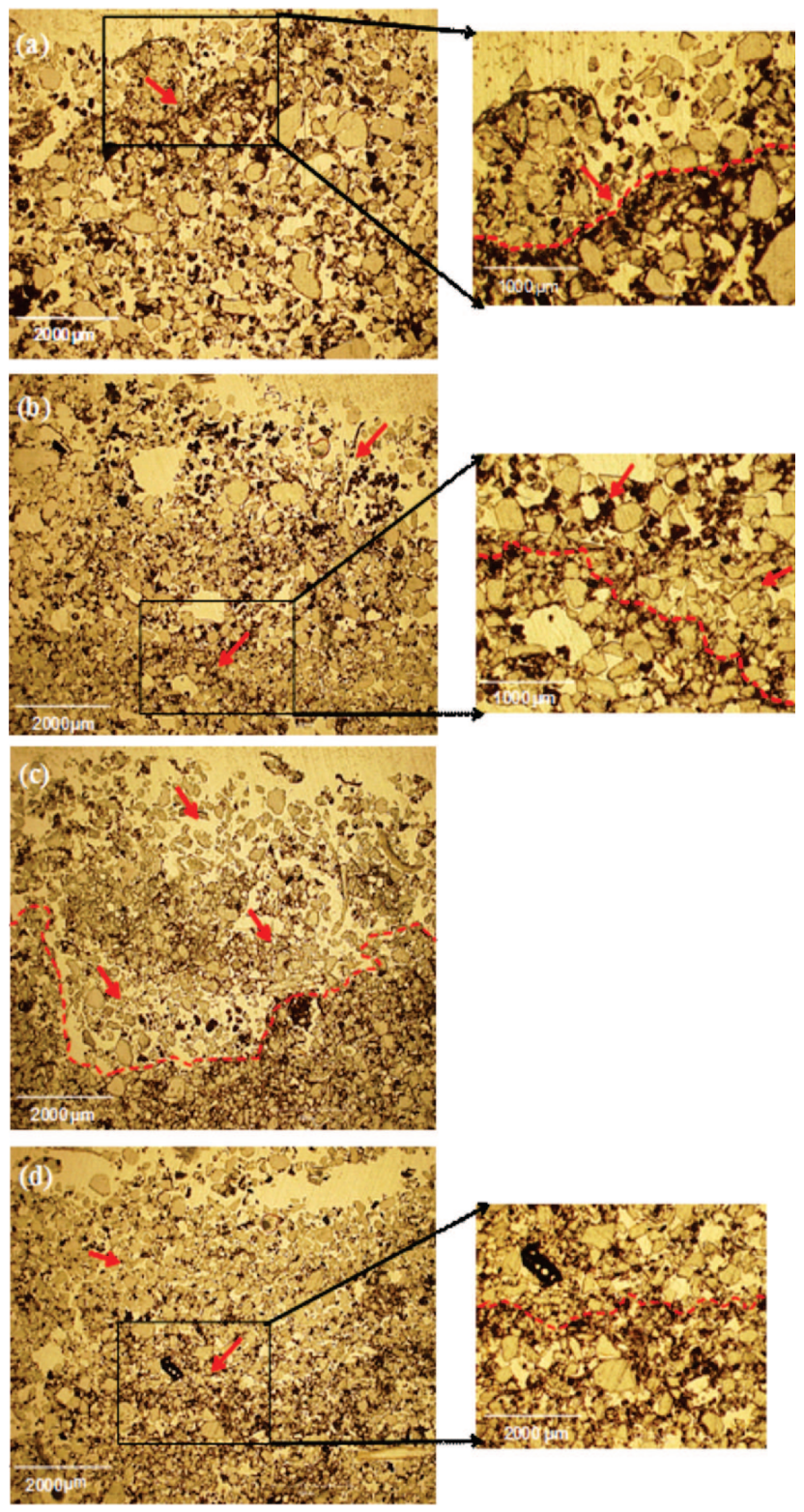

Figura 2. Detalhes da crosta formada no PR em função das lâminas de chuva aplicada, sobre um Argissolo Vermelho-Amarelo. (a), (b), (c), (d) correspondem a $0,27,54$ e $80 \mathrm{~mm}$, respectivamente. Setas nas figuras indicam material disperso acumulado, podendo ser zonas de material grosso ou fino. 
Quadro 3. Descrição micromorfológica para o sistema de PR em função das lâminas de chuva aplicada sobre um Argissolo Vermelho-Amarelo

\begin{tabular}{|c|c|c|c|c|}
\hline \multirow{2}{*}{ Atributo } & \multicolumn{4}{|c|}{ Preparo reduzido } \\
\hline & $0 \mathrm{~mm}$ & $27 \mathrm{~mm}$ & $54 \mathrm{~mm}$ & $80 \mathrm{~mm}$ \\
\hline Geral & $\begin{array}{l}\text { Distribuição } \\
\text { heterogênea de material. } \\
\text { Duas zonas A }(70 \%) \text { e } \\
\text { B }(30 \%)\end{array}$ & $\begin{array}{l}\text { Distribuição heterogênea } \\
\text { de material. Duas zonas } \\
\text { A }(70 \%) \text { B }(30 \%)\end{array}$ & $\begin{array}{l}\text { Distribuição heterogênea } \\
\text { de material. Duas zonas } \\
\text { A }(80 \%) \text { B }(20 \%)\end{array}$ & $\begin{array}{l}\text { Distribuição heterogênea } \\
\text { de material. Duas zonas } \\
\text { A }(80 \%) \text { B }(20 \%)\end{array}$ \\
\hline Micro -estrutura & $\begin{array}{l}\text { A) Microgranular } \\
\text { adensada }(60 \%)+ \\
\text { Cavitária Irregular }(40 \%) \\
\text { B) Microagregados } \\
\text { intergrãos }\end{array}$ & $\begin{array}{l}\text { A) Cavitária Irregular; } \\
\text { B) Estrutura poro } \\
\text { vesicular }(40 \%)+ \\
\text { cavitária irregular }(60 \%)\end{array}$ & $\begin{array}{l}\text { A) Cavitária Irregular } \\
(60 \%)+\text { microgranular } \\
\text { adensada (40\%); B) } \\
\text { Microestrutura vesicular } \\
(80 \%)+\text { microgranular } \\
\text { coalescida }(20 \%)\end{array}$ & $\begin{array}{l}\text { A) Cavitária Irregular + } \\
\text { Blocos subangulares; } \\
\text { moderadamente } \\
\text { desenvolvidos; B) } \\
\text { Cavitária Irregular }\end{array}$ \\
\hline Material fino & $\begin{array}{l}\text { Argila e matéria } \\
\text { orgânica, marrom } \\
\text { escura, A) }(20 \%) \text {, } \\
\text { B) }(15 \%)\end{array}$ & $\begin{array}{l}\text { Argila e matéria } \\
\text { orgânica, marrom } \\
\text { escura, A) e B) (15 \%) }\end{array}$ & $\begin{array}{l}\text { Argila e matéria } \\
\text { orgânica, marrom escura, } \\
\text { A) }(20 \%), \text { B) }(15 \%)\end{array}$ & $\begin{array}{l}\text { Argila e matéria } \\
\text { orgânica, marrom escura, } \\
\text { A) }(20 \%) ; \text { B) }(15 \%)\end{array}$ \\
\hline Material grosso & $\begin{array}{l}\text { Quartzo } \\
\text { subarredondado, mal } \\
\text { selecionado; A) (40\%), } \\
\text { B) }(35 \%)\end{array}$ & $\begin{array}{l}\text { Quartzo } \\
\text { subarredondado, mal } \\
\text { selecionado; A) }(40 \%) \text {, } \\
\text { B) }(35 \%)\end{array}$ & $\begin{array}{l}\text { Quartzo subarredondado, } \\
\text { mal selecionado; } \\
\text { A) } 40 \%), \text { B) }(35 \%)\end{array}$ & $\begin{array}{l}\text { Quartzo subarredondado, } \\
\text { mal selecionado; A) (40\%) } \\
\text { B) }(35 \%)\end{array}$ \\
\hline Poros & $\begin{array}{l}\text { A) }(40 \%) \text { Predomínio de } \\
\text { cavidades irregulares; } \\
\text { B) }(50 \%) \text { Predomínio de } \\
\text { cavidades irregulares e } \\
\text { vesículas }\end{array}$ & $\begin{array}{l}\text { A) }(45 \%) \text { Predomínio de } \\
\text { cavidades irregulares; } \\
\text { B) }(50 \%) \text { Predomínio de } \\
\text { cavidades irregulares e } \\
\text { vesículas }\end{array}$ & $\begin{array}{l}\text { A) }(40 \%) \text { Predomínio de } \\
\text { cavidades irregulares; } \\
\text { B) }(50 \%) \text { Predomínio de } \\
\text { cavidades irregulares e } \\
\text { vesículas }\end{array}$ & $\begin{array}{l}\text { A) }(40 \%) \text { Predomínio de } \\
\text { cavidades e fissuras; } \\
\text { B) }(40 \%) \text { Predomínio de } \\
\text { cavidades e vesículas }\end{array}$ \\
\hline $\begin{array}{l}\text { Distribuição } \\
\text { relativa }\end{array}$ & $\begin{array}{l}\text { A) Quito-Enáulica com } \\
\text { domínios porfíricos; B) } \\
\text { Quito-Gefurica Enáulica }\end{array}$ & $\begin{array}{l}\text { A) Quito-Enáulica- } \\
\text { Gefúrica com domínios } \\
\text { porfíricos na forma de } \\
\text { blocos; B) Quito-Enáulica }\end{array}$ & $\begin{array}{l}\text { A) Quito-Enáulica com } \\
\text { domínios porfíricos na } \\
\text { forma de blocos; B) Quito- } \\
\text { Enáulica com pequenas } \\
\text { zonas Enáulica-Porfírica }\end{array}$ & $\begin{array}{l}\text { A) Quito-Enáulica com } \\
\text { domínios porfíricos na } \\
\text { forma de blocos; B) Quito- } \\
\text { Gefúrica-Enáulica com } \\
\text { pequenas zonas porfíricas }\end{array}$ \\
\hline $\begin{array}{c}\text { Feições } \\
\text { pedológicas }\end{array}$ & $\begin{array}{l}\text { A) não; B) Formação de } \\
\text { crosta muito } \\
\text { diferenciada do PC, } \\
\text { material em superfície } \\
\text { desorientado e poroso; } \\
\text { Presença de laminação } \\
\text { de argila no interior } \\
\text { desta camada, porém } \\
\text { não é constante ocorre } \\
\text { somente em algumas } \\
\text { partes desta camada. }\end{array}$ & $\begin{array}{l}\text { A) não; B) Formação de } \\
\text { crosta diferenciada, } \\
\text { material em superfície } \\
\text { desorientado e poroso; } \\
\text { Presença de laminações } \\
\text { de argila no interior } \\
\text { desta camada, porém não } \\
\text { é constante, ocorre em } \\
\text { maior frequência do que } \\
\text { onde não se aplicou } \\
\text { chuva. }\end{array}$ & $\begin{array}{l}\text { A) não; B) Formação de } \\
\text { crosta diferenciada, } \\
\text { material em superfície } \\
\text { muito desorientado e } \\
\text { poroso; Laminação de } \\
\text { argila menos evidente, } \\
\text { somente em pontos } \\
\text { específicos e na superfície } \\
\text { da lâmina, porém não é } \\
\text { constante. Indicação de } \\
\text { bolsões de acumulo de } \\
\text { areia em algumas zonas. }\end{array}$ & $\begin{array}{l}\text { A) não; B) Formação de } \\
\text { crosta diferenciada, } \\
\text { material em superfície } \\
\text { desorientado e poroso; } \\
\text { Presença de laminação de } \\
\text { argila no interior desta } \\
\text { camada, mais evidente } \\
\text { que as anteriores; } \\
\text { Presença de um bolsão de } \\
\text { acúmulo de areia. }\end{array}$ \\
\hline
\end{tabular}

\section{Formação de crostas no SP em razão das lâminas de chuva aplicada}

A cobertura permanente pela palhada de braquiária protegeu a superfície do solo do impacto direto da gota, não atingindo e não modificando a superfície por causa das lâminas de chuva aplicada, como observado no PC. Entretanto, constatou-se recobrimento da superfície do solo (Figura 3a,c), o que possivelmente seja em razão do acúmulo do material fino disperso pelo molhamento.

Esse sistema de preparo apresentou pouca modificação estrutural da superfície do solo em razão das chuvas aplicadas. Com aplicação de uma lâmina de chuva inicial ( $27 \mathrm{~mm}$ ), a superfície se apresentou mais perturbada, mas, de maneira geral, foram observadas algumas feições de acúmulo de material fino superficialmente e, em outros casos, internamente nos primeiros centímetros do solo, independentemente da chuva aplicada.

As feições observadas de laminações de material fino acumulado podem ter sido originadas pelo efeito da chuva natural, uma vez que foram também constatadas onde não houve aplicação de chuva simulada $(0 \mathrm{~mm})$. Pelo efeito do umedecimento, ocorre 

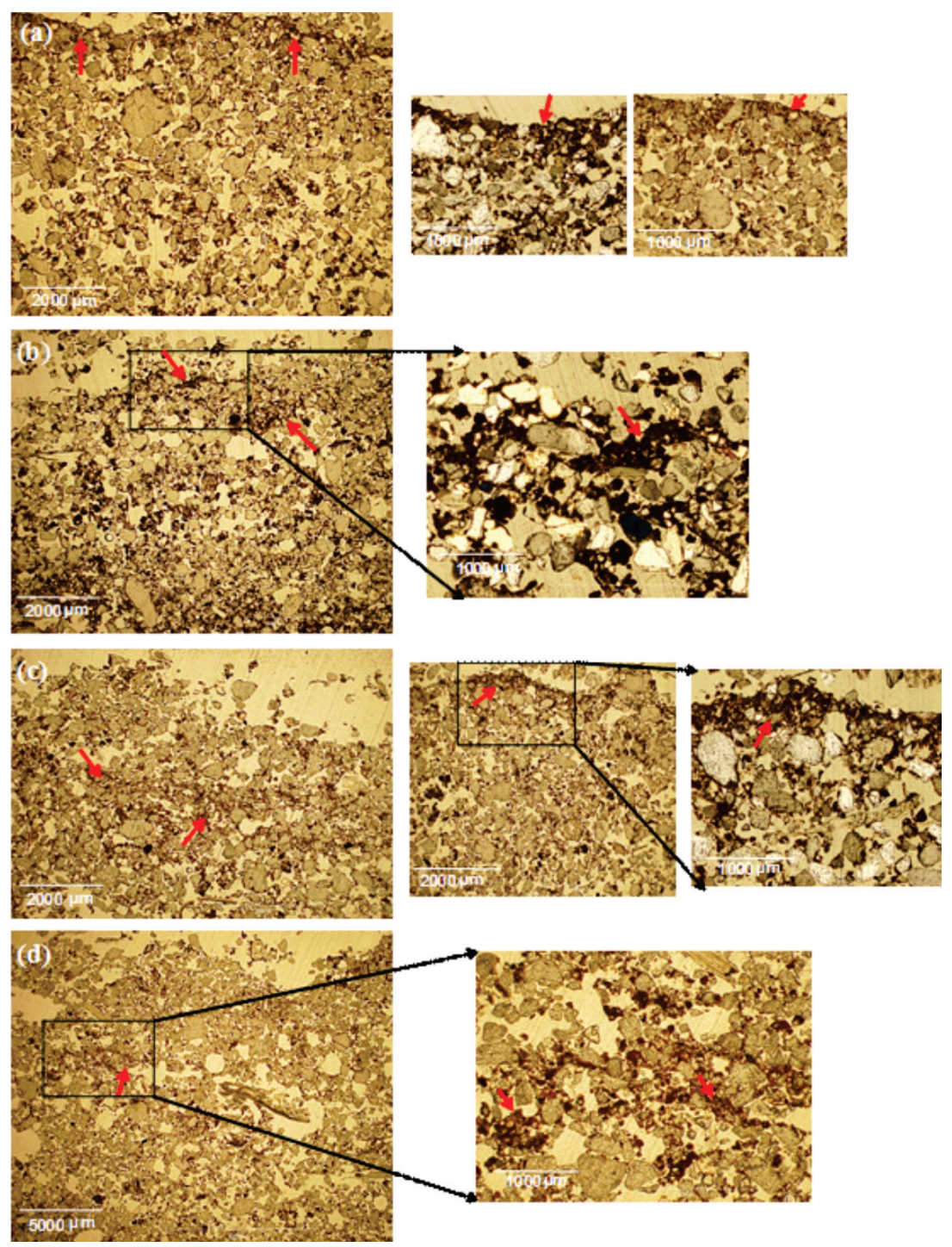

Figura 3. Detalhes da crosta formada no SP em razão das lâminas de chuva aplicada, sobre um Argissolo Vermelho-Amarelo. (a), (b), (c), (d) correspondem a 0, 27, 54 e $80 \mathrm{~mm}$, respectivamente. Setas nas figuras indicam material disperso acumulado, podendo ser zonas de material grosso ou fino.

a dispersão do material fino do solo que vai sendo depositado em lâminas pela infiltração de água (Agassi et al., 1981); possivelmente esse seja o processo ocorrido nesse sistema de preparo, uma vez que em razão da grande quantidade de cobertura vegetal não ocorreu desagregação pelo impacto da gota. A não modificação da estrutura superficial do solo nesse sistema de preparo, diferente do observado no PC (organização e disposição vertical de grãos de quartzo), é atribuída à presença abundante de cobertura (superfície $100 \%$ coberta), que protegeu a superfície do solo evitando a ação desagregante da gota da chuva.

Essas feições observadas nesse sistema de preparo foram constatadas nos dois anos de estudo, de maneira um pouco diferenciada entre as chuvas aplicadas. As crostas nesse sistema de preparo foram classificadas como estruturais do tipo Slaking, conforme classificação de Valentin \& Bresson (1992). O acúmulo de material fino ocorreu recobrindo algumas áreas do topo da superfície e outras áreas internamente na camada superficial (Figura 3).

Nesse sistema de preparo houve o domínio de poros do tipo cavidades irregulares e vesículas (Quadro 4), o que pode ser consequência da falta de revolvimento do solo. Os poros do tipo vesículas geralmente apresentam forma arredondada e não possuem conexão com outros, ocasionando dessa forma a redução dos fluxos hidráulicos do solo.

Como a avaliação da formação de crostas em sistemas, onde o solo não é revolvido ainda, é escassa, salienta-se que estudos futuros em outros tipos de solos ainda fazem-se necessários para confirmação dos resultados apresentados neste trabalho. 
Quadro 4. Descrição micromorfológica para o sistema SP em razão das lâminas de chuva aplicada sobre um Argissolo Vermelho-Amarelo

\begin{tabular}{|c|c|c|c|c|}
\hline \multirow{2}{*}{ Atributo } & \multicolumn{4}{|c|}{ Sem preparo } \\
\hline & $0 \mathrm{~mm}$ & $27 \mathrm{~mm}$ & $54 \mathrm{~mm}$ & $80 \mathrm{~mm}$ \\
\hline Geral & $\begin{array}{l}\text { Distribuição } \\
\text { heterogênea de } \\
\text { material. Duas zonas } \\
\text { A }(20 \%) \text { e B }(80 \%)\end{array}$ & $\begin{array}{l}\text { Distribuição heterogênea } \\
\text { de material. Duas zonas } \\
\text { A }(30 \%) \text { e B }(70 \%)\end{array}$ & $\begin{array}{l}\text { Distribuição } \\
\text { heterogênea de } \\
\text { material. Duas zonas } \\
\text { A }(70 \%) \text { e B }(30 \%)\end{array}$ & $\begin{array}{l}\text { Distribuição heterogênea de } \\
\text { material. Duas zonas A ( } 80 \text { \%) } \\
\text { e B }(20 \%)\end{array}$ \\
\hline $\begin{array}{l}\text { Micro - } \\
\text { estrutura }\end{array}$ & $\begin{array}{l}\text { A) Microgranular } \\
\text { adensada }+ \\
\text { microagregados } \\
\text { intergrãos; B) Cavitária } \\
\text { irregular }\end{array}$ & $\begin{array}{l}\text { A) Microgranular } \\
\text { adensada + cavitária } \\
\text { irregular; B) cavitária } \\
\text { irregular + estrutura poro } \\
\text { - vesicular intergrãos }\end{array}$ & $\begin{array}{l}\text { A) Microgranular } \\
\text { adensada + cavitária } \\
\text { irregular } \\
\text { microagregados } \\
\text { intergrãos; B) vesicular } \\
(80 \%)+\text { microgranular } \\
\text { coalescida }(20 \%)\end{array}$ & $\begin{array}{l}\text { A) Microgranular adensada + } \\
\text { cavitária irregular; B) } \\
\text { Cavitária irregular }\end{array}$ \\
\hline $\begin{array}{l}\text { Material } \\
\text { fino }\end{array}$ & $\begin{array}{l}\text { Argila e matéria } \\
\text { orgânica, marrom } \\
\text { escura, A) }(25 \%) \text {, } \\
\text { B) }(15 \%)\end{array}$ & $\begin{array}{l}\text { Argila e matéria orgânica, } \\
\text { marrom escura,A) }(25 \%), \\
\text { B) }(15 \%)\end{array}$ & $\begin{array}{l}\text { Argila e matéria } \\
\text { orgânica, marrom } \\
\text { escura, A) }(25 \%) \text {, } \\
\text { B) }(15 \%)\end{array}$ & $\begin{array}{l}\text { Argila e matéria orgânica, } \\
\text { marrom escura, A) e } \\
\text { B) }(25 \%)\end{array}$ \\
\hline $\begin{array}{c}\text { Material } \\
\text { grosso }\end{array}$ & $\begin{array}{l}\text { Quartzo } \\
\text { subarredondado, mal } \\
\text { selecionado, A) e } \\
\text { B) } 40 \% \text { ) }\end{array}$ & $\begin{array}{l}\text { Quartzo subarredondado, } \\
\text { mal selecionado,A) e } \\
\text { B) }(40 \%)\end{array}$ & $\begin{array}{l}\text { Quartzo } \\
\text { subarredondado, mal } \\
\text { selecionado, A) e } \\
\text { B) }(35 \%)\end{array}$ & $\begin{array}{l}\text { Quartzo subarredondado, mal } \\
\text { selecionado; A) (40\%); } \\
\text { B) }(35 \%)\end{array}$ \\
\hline Poros & $\begin{array}{l}\text { A) }(35 \%) \text { Predomínio de } \\
\text { cavidades, vesículas, } \\
\text { fissuras e poros de } \\
\text { empilhamento B) }(45 \%) \\
\text { Predomínio de cavidades }\end{array}$ & $\begin{array}{l}\text { A) }(35 \%) \text { Predomínio de } \\
\text { cavidades, canais, fissuras } \\
\text { e poros de empilhamento; } \\
\text { B) Cavidade e vesículas }\end{array}$ & $\begin{array}{l}\text { A) }(40 \%) \text { Cavidades, } \\
\text { irregulares (dominante) } \\
\text { e poros de } \\
\text { empilhamento; } \\
\text { B) (50\%) vesículas e } \\
\text { Cavidades }\end{array}$ & $\begin{array}{l}\text { A) }(35 \%) \text { Cavidades } \\
\text { irregulares, canais, fissuras e } \\
\text { poros de empilhamento; } \\
\text { B) }(40 \%) \text { Predomínio de } \\
\text { cavidades }\end{array}$ \\
\hline $\begin{array}{l}\text { Distribuição } \\
\text { relativa }\end{array}$ & $\begin{array}{l}\text { A) Enáulica-Porfírica } \\
\text { com zonas Quito- } \\
\text { Gefúrica-Enáulica; } \\
\text { B) Quito - Gefúrica - } \\
\text { Enáulica }\end{array}$ & $\begin{array}{l}\text { A) Quito-Gefúrica- } \\
\text { Enáulica com zonas } \\
\text { porfíricas; B) Quito - } \\
\text { Gefúrica - Enáulica }\end{array}$ & $\begin{array}{l}\text { A) Quito - Porfírica com } \\
\text { pequenas zonas } \\
\text { porfíricas; B) Quito- } \\
\text { Porfírica - Enáulica }\end{array}$ & $\begin{array}{l}\text { A) Enáulica - Porfírica; } \\
\text { B) Quito - Gefúrica - Enáulica }\end{array}$ \\
\hline $\begin{array}{c}\text { Feições } \\
\text { pedológicas }\end{array}$ & $\begin{array}{l}\text { A) não; B) Evidencias de } \\
\text { material fino recobrindo } \\
\text { a superfície do solo, } \\
\text { porém não é constante } \\
\text { em toda superfície da } \\
\text { lâmina. Material da } \\
\text { superfície mais solto e } \\
\text { desorientado do que em } \\
\text { subsuperfície. }\end{array}$ & $\begin{array}{l}\text { A) Presença de } \\
\text { excrementos, pouco } \\
\text { envelhecido, não } \\
\text { incorporado ao solo. Não } \\
\text { rugoso, redondo, } 3 \text { \%; } \\
\text { B) Evidencias de material } \\
\text { fino recobrindo a } \\
\text { superfície do solo, porém } \\
\text { não é constante em toda } \\
\text { superfície. Material da } \\
\text { superfície mais solto e } \\
\text { desorientado do que em } \\
\text { subsuperfície. }\end{array}$ & $\begin{array}{l}\text { A) não; B) Material da } \\
\text { superfície mais solto e } \\
\text { desorientado do que em } \\
\text { subsuperfície; Presença } \\
\text { de laminações de } \\
\text { material fino } \\
\text { permeando esta camada } \\
\text { de material } \\
\text { desorientado. }\end{array}$ & $\begin{array}{l}\text { A) não; B) Evidencias de } \\
\text { material fino recobrindo a } \\
\text { superfície do solo, porém não é } \\
\text { constante em toda superfície da } \\
\text { lâmina. Material da superfície } \\
\text { mais solto e desorientado do } \\
\text { que em subsuperfície. }\end{array}$ \\
\hline
\end{tabular}

\section{CONCLUSÕES}

1. Os sistemas de preparo avaliados neste estudo demonstraram presença de crostas; entretanto, o processo de formação das crostas ocorreu com dinâmica diferenciada em cada sistema de preparo.

2. O preparo convencional apresentou formação de crostas a partir de $27 \mathrm{~mm}$ de chuva aplicada. O aumento da lâmina de chuva causou maior degradação da estrutura superficial e maior espessura da camada encrostada, em relação aos demais sistemas de preparo.

3. O preparo reduzido e o sistema sem preparo desenvolveram crostas irregulares, ou seja, não demonstraram modificações constantes na superfície do solo e na formação das crostas, com o aumento da chuva, como constatado no preparo convencional.

4. A análise das lâminas delgadas e a descrição micromorfológica permitiram satisfatória observação 
e conclusão dos processos e da dinâmica envolvida na formação de crostas.

\section{AGRADECIMENTOS}

À Fundação de Amparo à Pesquisa do Estado de São Paulo (FAPESP), pela bolsa de estudos e pelo auxílio financeiro para desenvolvimento do projeto (Processo 2008/53591-08). Ao Conselho Nacional de Desenvolvimento Científico e Tecnológico pela bolsa de produtividade concedida.

\section{LITERATURA CITADA}

AGASSI, M.; SHAINBERG, I. \& MORIN, J. Effect of electrolyte concentration and soil sodicity on the infiltration rate and crust formation. Soil Sci. Soc. Am. J., 45:848-881, 1981.

BASE DE DADOS METEOROLÓGICOS, USP/ESALQ. Disponíve em: <http://www.leb.esalq.usp.br/ postoaut.html>. Acesso em: 20 set. 2011. USP/ESALQDepartamento de Engenharia e Biossistemas.

BEDAIWY, M.N.A. Mechanical and hydraulic resistance relations in crust-topped soils. Catena, 72: 270-281, 2008.

BRANDÃO, V.S.; SILVA, D.D.; RUIZ, H.A.; PRUSKI, F.F.; SCHAEFER, C.E.G.R.; MARTINEZ, M.A. \& MENEZES, S.J.M.C. Resistência hidráulica da crosta formada em solos submetidos a chuvas simuladas. R. Bras. Ci. Solo, 30:13-21, 2006.

BRESSON, L.M. \& BOIFFIN, J. Morphological characterization of soil crust development stages on an experimental field. Geoderma, 47:301-325, 1990.

BRESSON, L.M. \& VALENTIN, C. Soil surface crust formation: Contribution of micromorphology. In: RINGROSE-VOASE,A.J. \& HUMPHREYS, G.S., eds. Developments in Soil Science. Amsterdam, Elsevier, 1993. p.737-762.

BREWER, R. Fabric and mineral analysis of soils. New York, John Wiley \& Sons, 1964. 482p.

BULLOCK, P.; FEDOROFF, N.; JONGERIUS, A.; STOOPS, G. \& TURSINA, T. Handbook for soil thin section description. Wolverhampton, Waine Research Publications,1985. 153p.

CASTRO, S.S.; COOPER, M.; SANTOS, M.C. \& VIDALTORRADO, P. Micromorfologia do solo: Bases e aplicações. In: CURI, N.; MARQUES, J.J.; GUILHERME, L.R.G.; LIMA, J.M.; LOPES, A.S. \& ALVAREZ V., V.H., eds. Tópicos em ciência do solo. Viçosa, MG, Sociedade Brasileira de Ciência do Solo, 2003. v.3. p.107-164.

DULEY, F. Surface factors affecting the rate of intake of water by soils. Soil Sci. Soc. Am. Proc., 4: 60-64, 1939.
EMPRESA BRASILEIRA DE PESQUISA AGROPECUÁRIA EMBRAPA. Sistema brasileiro de classificação de solos. 2.ed. Brasília, Embrapa Sistemas de Informação; Rio de Janeiro, Embrapa Solos, 2006. 306p.

FOX, D.M.; LE BISSONNAIS, Y. \& BRUAND, A. The effect of ponding depth on infiltration in a crusted surface depression. Catena, 32:87-100, 1998.

FOX, D.M. \& LE BISSONNAIS, Y. A process-based analysis of the influence of aggregate stability on surface crusting, infiltration, and interrill erosion. Soil Sci. Soc. Am. J., 62:717-724, 1998.

JONGERIUS, A. Some morphological aspects of regrouping phenomena in Dutch soils. Geoderma, 4:311-331, 1970.

LADO, M.; PAZ, A. \& BEN-HUR, M. Organic matter and aggregate size interactions in infiltration, seal formation, and soil loss. Soil Sci. Soc. Am. J., 68:935-942, 2004.

LE BISSONNAIS, Y.; CERDAN, O.; LECOMTE, V.; BENKHADRA, H.; SOUCHERE, V. \& MARTIN, P. Variability of soil surface characteristics influencing runoff and interrill erosion. Catena, 62:111-124, 2005.

LE BISSONNAIS, Y. \& SINGER, M.J. Seal formation, runoff and interrill erosion from 17 California soils. Soil Sci. Soc. Am. J., 57:224-229, 1993.

LIMA, H.V.; LIMA, R.L.C.; LEÃO, T.P.; COOPER, M.; SILVA, A.P. \& ROMERO, R.E. Tráfego de máquinas agrícolas e alterações de bioporos em área sob pomar de laranja. R. Bras. Ci. Solo, 29:677-684, 2005.

McINTYRE, D.S. Permeability measurements of soil crusts formed by raindrop impact. Soil Sci. Soc. Am. J., 85:185189, 1958.

MURPHY, C.P. Thin section preparation of soils and sediments. Berkhamsted, A.B. Academic Publication, 1986.149p.

MURPHY, C.P.; BULLOCK, P. \& TURNER, R.H. The measurement and characterization of voids in soil thin sections by image analysis. Part I. Principles and techniques. J. Soil Sci., 98:498-508, 1977.

RIES, J.B. \& HIRT, U. Permanence of soil surface crusts on abandoned farmland in the Central Ebro Basin/Spain. Catena, 72:282-296, 2008.

SCHAEFER, C.E.G.R.; SILVA, D.D.; PAIVA, K.W.N.; PRUSKI, F.F.; ALBUQUERQUE FILHO, M.R. \& ALBUQUERQUE, M.A. Perdas de solo, nutrientes, matéria orgânica e efeitos microestruturais em Argissolo Vermelho-Amarelo sob chuva simulada. Pesq. Agropec. Bras. 37:668-679, 2002.

SHAINBERG, I.; LEVY, G.J.; RENGASAMY, P. \& FRENKEL, H. Aggregate stability and seal formation as affected by drops impact energy and soil amendments. Soil Sci., 54:113-119, 1992.

VALENTIN, C. \& BRESSON, L.M. Morphology, genesis and classification of surface crusts in loamy and sandy soils. Geoderma, 55:225-245, 1992.

VALENTIN, C. \& BRESSON, L.M. Soil crusting. In: LAL, R.; BLUM, W.H.; VALENTIN, C. \& STEWART, B.A., eds. Methods for assessment of soil degradation. Boca Raton, CRC Press, 1997. p.89-107. (Advances in Soil Science) 